\title{
Development, Characterisation and Evaluation of PVP K-30/PEG Solid Dispersion Containing Ketoprofen
}

\author{
Meenakshi Bhatia $^{1^{*}}$, Sunita Devi ${ }^{1}$ \\ 1 Guru Jambheshwar University of Science and Technology, Pharmaceutical Sciences, Hisar, India
}

\begin{abstract}
The present study is designed with the objective to enhance the aqueous solubility of ketoprofen. For the said purpose solid dispersion employing PVP K-30 and PEG 6000 is prepared by hot melt method. The preparation of solid dispersion (SD) was optimized using 2-factor, 3 level central composite design. The preparation of SD was characterized by FTIR, DSC, XRD and SEM studies. Further, solubility, Gibb's energy and in vitro release study was determined for different batches of the formulation as suggested by the design expert. The solubility of different batches of SD was found to be between 36.2 to $53.0 \mu \mathrm{g} / \mathrm{ml}$ whereas pure drug and physical mixture possess the solubility of 14.4 and $23.8 \mu \mathrm{g} / \mathrm{mL}$, respectively. The in vitro release is found to be 76.74 to $95.32 \%$ and PM shows $75.4 \%$ release and pure drug shows $23.5 \%$ release. Thus, the ketoprofen-loaded solid dispersion would be useful for delivering poorly water-soluble ketoprofen with enhanced dissolution, solubility and no crystalline changes.
\end{abstract}

Keywords: Ketoprofen, solid dispersion, dissolution rate, solubility study.

\section{INTRODUCTION}

Poor aqueous solubility of pharmaceutically active ingredients has been a challenge to the researchers. More than $40 \%$ of newly developed drugs candidates are poorly water soluble ${ }^{1}$. This low aqueous solubility further lowers the absorption in GI tract and thus reduced bioavailability is observed. Therefore, the development of new techniques to enhance drug solubility remains one of the major research areas in drug discovery and development process ${ }^{2}$. A scan of literature has revealed that numerous attempts has been made to improve the

${ }^{*}$ Corresponding Author: Meenakshi Bhatia, e-mail: meenaxibhatia@gmail.com

Meenakshi Bhatia ORCID Number: 0000-0003-4568-7582

Sunita Devi ORCID Number: 0000-0002-1660-8550

(Received 04 September 2019, accepted 05 November 2019) 
solubility and dissolution of drugs that include cyclodextrins complexes ${ }^{3}$, drug micronization in to amorphous form ${ }^{4}$, prodrug formation ${ }^{5}$, solid dispersion ${ }^{6,-12}$, salt formation ${ }^{13}$, solubilization of drug in solvents, nanoparticles technology ${ }^{14}$, physical modification, nanosuspension ${ }^{15-19}$, modification of crystal habit such as polymorphus, pseudo polymorphous, self-emulsifying drug delivery systems ( SEDDS) ${ }^{20}$, liposomes ${ }^{21-25}$ and use of surfactant " micelization" ${ }^{26}$ etc. Out of numerous techniques explored so far solid dispersion have been proved to be the most promising strategy to improve the solubility of poorly watersoluble drugs. In solid dispersion compounds are mixed / dispersed in solid state in a suitable carrier or matrix to deliver the insoluble compounds ${ }^{27}$. Solid dispersions preparation by hot melt or fusion method is preferred because of it is simple and is useful for the compounds that do not undergo significant thermal degradation. Further toxicity and environmental issues that are associated with use of organic solvents make the technique more preferable ${ }^{28}$.

Ketoprofen, categorized as BCS class II drug, is a safe propionic acid derivative non-steroidal anti-inflammatory drug. However, its poor water solubility (o.13 $\mathrm{mg} / \mathrm{ml}$ at $25^{\circ} \mathrm{C}$ ) limits its absorption and dissolution rate that results in delayed onset of action. Therefore, its incorporation in water soluble matrix solid dispersion have been considered as an effective method for improving its dissolution rate and solubility. A number of efforts have been made to incorporate ketoprofen into solid dispersion using mannitol, urea, PVP K-30 ${ }^{29}$, PVP K-30 and D-mannitol ${ }^{30}$, bovine serum albumin ${ }^{12}$, Macrogal and Kollagen ${ }^{31}$ and PEG $6000^{32}$. On scouring the literature, it is observed that PVP and PEG are most popularly used polymers for the preparation of solid dispersion ${ }^{33}$. Low melting point of PEG $\left(50-60^{\circ} \mathrm{C}\right)$ and rapid solidification offers it to be used in forming solid dispersion ${ }^{25}$ while the PVP K-30 is high melting point $\left(150-180^{\circ} \mathrm{C}\right)$ and small its molecular weight render it to be a suitable carrier in achieving high dissolution ${ }^{34}$.

The present study is designed to obtain solid dispersion of ketoprofen with PEG 6000 and PVP K-30 using hot melt or fusion method with the objective to enhance solubility and dissolution of the drug. The preparation of solid dispersion was optimized by using 3 factor 2 level central composite experimental design. The optimized batch was characterized by FTIR, SEM, DSC, XRD spectra and evaluated for its in-vitro release behavior and solubility.

\section{METHODOLOGY}

\section{Materials}

Ketoprofen was obtained as a gift sample from Infinity Laboratories Pvt. Ltd 
(Behra, India). Polyvinyl pyrrolidone (PVP) K30 (kollidon K30) and polyethylene glycol 6000(PEG 6000) (PEG 6000) was supplied by Symmetry laboratories, Faridabad. All other reagents and chemicals used in the study were of analytical grade and used as received.

\section{Methods}

\section{Preparation of solid dispersion}

SDs of ketoprofen were prepared by using hot melt technique by mixing required quantities of ketoprofen(100 mg),PVP K-30 and PEG 6000 as displayed in Table 1. The ingredients were added in decreasing order of their melting point and the resulting homogeneous preparation was cooled and stored in a desiccator for $24 \mathrm{~h}$. Subsequently, the dispersion was ground using a mortar and sieved through a \#100 sieve.

Physical mixtures (PM) was prepared by thoroughly mixing presieved equal weight ratio of ketoprofen, PEG 6000 and PVP K-30 using pestle and mortar until a homogeneous mixture was obtained.

\section{Experimental design}

The preparation of solid dispersion using PVP K-30 and PEG 60oo was optimized using 2-factor, 3 level central composite design. The concentration of PEG $6000\left(\mathrm{X}_{1}\right)$ and concentration of PVP K-30 $\left(\mathrm{X}_{2}\right)$ were selected as the formulation variables while the $\%$ drug release, solubility $(\mu \mathrm{g} / \mathrm{ml})$ and Gibb's energy $(\mathrm{kg} / \mathrm{mol})$ were chosen as response variables. Each independent variable was investigated at three levels (i.e. -1, o, and 1). The experimental design and statistical analysis of the data was done by using Design Expert software (version 11.0).

\section{Determination of drug content}

The different batches of solid dispersions and physical mixture (PM) containing ketoprofen equivalent to 10mg were dissolved separately in $25 \mathrm{ml}$ of phosphate buffer (pH 7.4). Samples were filtered through $0.45 \mu \mathrm{m}$ milipore filters and after appropriate dilution were analyzed by UV visible spectrophotometer at $260 \mathrm{~nm}$. The drug content was determined using calibration curve.

\section{Characterization of solid dispersion}

\section{Fourier Transform Infrared Spectroscopy (FT-IR)}

FT-IR spectroscopy is employed to characterize the possible interactions between the drug and the carrier in the solid state. FTIR spectra of powder samples of ketoprofen, PEG 6000, physical mixture and solid dispersion were ob- 
tained using a spectrophotometer (FTIR-8300, Shimadzu co., Kyoto, Japan) by using potassium bromide $(\mathrm{KBr})$ pellet method in the scanning range of 400$4000 \mathrm{~cm}^{-1}$.

\section{Powder X-ray diffraction (PXRD)}

PXRD is the most important tool to determine the structure of the compound. Powder XRD patterns were traced employing X-ray diffractometer (Philips PW 1830, the Netherlands) for the samples of ketoprofen, PVP K-30, PEG 6000, physical mixture and solid dispersion using Ni filtered Cuka radiation of wavelength $1.5404 \mathrm{~A}^{\circ}$, a voltage of $35 \mathrm{kV}$, a current of $30 \mathrm{~mA}$ and receiving slit of $0.1 \mathrm{~mm}$. The sample were analyzed over $2 \theta$ range of $5-50^{\circ}$.

\section{Scanning electron microscopy (SEM)}

The particle shape and morphology of the sample was investigated using SEM (JEPL, JSM-6100). The samples for SEM were mounted on sample holder with double-sided adhesive tape after vacuum coated with gold.

\section{Differential scanning Calorimetry (DSC)}

DSC analysis of samples ketoprofen, PVP K-30, PEG 6000, physical mixture and solid dispersion was carried out using DSC (Q10 V9.9 Build 303, US). Each sample was heated at the scanning rate of $10^{\circ} \mathrm{C} / \mathrm{min}$, from 30 to $200^{\circ} \mathrm{C}$.

\section{Solubility studies}

Ketoprofen pure drug, PM and solid dispersion containing ketoprofen equivalent to $10 \mathrm{mg}$ was dispersed in $10 \mathrm{ml}$ of distilled water and kept on shaker for $48 \mathrm{hrs}$ at room temperature $\left(25^{\circ} \mathrm{C}\right)$ to determine the solubility of ketoprofen. The obtained solution was filtered by $0.45 \mu \mathrm{m}$ milipore filter paper and the drug content was determined by taking absorbance at $260 \mathrm{~nm}$ using $u v$-vis spectrophotometer. The amount of drug was calculated using the calibration curve in water. The Gibbs free energy of transfer $(\Delta G)$ of drug from water to the aqueous solution of carrier was calculated as equation 1.

$\Delta \mathrm{G}=-2.303 \mathrm{RT} \log \mathrm{S}_{\mathrm{o}} / \mathrm{S}_{\mathrm{s}}$

where $S_{o} / S_{s}$ is the ratio of solubility of ketoprofen in aqueous solution of carrier to that of the same medium without carrier.

\section{In vitro drug release}

In vitro dissolution studies were performed using the USP type II dissolution apparatus. Dissolution studies of pure drug (ketoprofen), PM and solid dispersions containing ketoprofen equivalent to $10 \mathrm{mg}$ were conducted in $300 \mathrm{ml}$ 
phosphate buffer ( $\mathrm{pH} 7.4$ ) at $37 \pm 0.5^{\circ} \mathrm{C}$ with constant stirring rate of $50 \mathrm{rpm}$. The powders were dispersed over the dissolution medium. Aliquots of sample $(5 \mathrm{ml})$ was withdrawn at different time intervals and replaced with an equal amount of the dissolution medium to maintain a constant volume. Samples were filtered through $0.45 \mu \mathrm{m}$ milipore filters and analyzed by uv-vis spectrophotometer at $260 \mathrm{~nm}$. The mechanism of drug release from the solid dispersion was determined by fitting the release data to several models like zero order, first- order, Higuchi and Korsmeyer-Peppas model.

\section{RESULTS AND DISCUSSION}

\section{Drug content of formulations}

The content of ketoprofen in different batches of SD was determined by carrying out the assay of drug by $u v$-vis spectroscopy is displayed in Table-1. The drug content was found to be between 82.8 to $97.9 \%$ whereas for PM containing equal amount of ingredients has drug content of $84.4 \%$. From the data it is clearly indicated that the drug content in the formulated batches of SD and PM is quite handsome indicating that drug is for entrapped/present in a sufficient amount.

\section{Fourier Transform Infrared Spectroscopy (FT-IR)}

Characteristic IR absorption peaks of ketoprofen were detected at $2979.23 \mathrm{~cm}^{-1}$ due to $-\mathrm{CH}$ stretching, $1694 \mathrm{~cm}^{-1}\left(-\mathrm{C}=\mathrm{O}\right.$ stretching of acid), $1654 \mathrm{~cm}^{-1}(-\mathrm{C}=\mathrm{O}$ stretching of ketone), 1598, 1583, $1457 \mathrm{~cm}^{-1}$ (-C=O stretching of aromatic ring), $1420 \mathrm{~cm}^{-1}$ (-C-H deformation of $\mathrm{CH}_{3}$ asymmetrical) and $1370 \mathrm{~cm}^{-1}$ (-C-H deformation of $\mathrm{CH}_{3}$ symmetrical) respectively ${ }^{12}$.

Important vibrations detected in the spectrum of $\mathrm{PEG}$ are the $-\mathrm{C}-\mathrm{H}$ stretching at $2889 \mathrm{~cm}^{-1}$ and the $-\mathrm{C}-\mathrm{O}$ (ether) stretching at $1112 \mathrm{~cm}^{-1}$. The $-\mathrm{OH}$ group is indicated by a strong band around $2890 \mathrm{~cm}^{-1}$. The region from $2700-3000 \mathrm{~cm}^{-1}$ in the spectra of pure ketoprofen, PEG 6000, PM and SD exhibited peaks assigned to aliphatic-C-H stretching ${ }^{35}$.

IR spectra of SD was found to be almost similar with that of PM because characteristic peaks representing specific functional group were detected. Especially the peak at $2888 \mathrm{~cm}^{-1}$ resulting from $-\mathrm{C}-\mathrm{H}$ stretching vibration was observed in both SD and PM of ketoprofen ${ }^{36}$. So the characteristic peaks of ketoprofen also seen in SD and PM that indicate that ketoprofen is present in the SD and PM. 


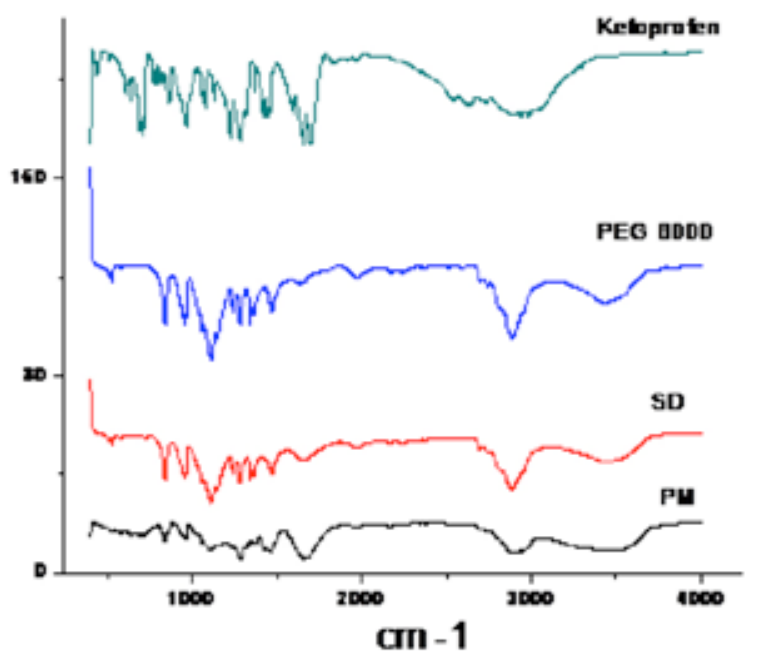

Figure 1. FTIR spectra of pure ketoprofen, PEG 6000, SD and physical mixture.

\section{Power X-ray diffraction (PXRD)}

The powder XRD of pure ketoprofen, physical mixtures, polymers PEG 6000, PVP K-30 and solid dispersion are shown in figure 2. The presence of numerous distinct peaks in the X-ray-diffraction spectrum of ketoprofen indicates that ketoprofen is present as a crystalline material with characteristics sharp peaks appearing at a diffraction angle of $2 \theta$ at 18.608, 22.976 and 27.23 etc. XRD spectra of PVP K-30 showed no intrinsic peaks at the diffraction angles examined, which is typical of amorphous sample. PEG 6000 exhibited a distinct pattern with diffraction peaks at $2 \theta$ of 19.12, 23.504, revealing its crystalline nature. As expected, all major characteristic crystalline peaks for the drug were also observed in the SD and PM. These results indicated that ketoprofen was present in an unchanged crystalline state in the $\mathrm{SD}^{37-39}$. 


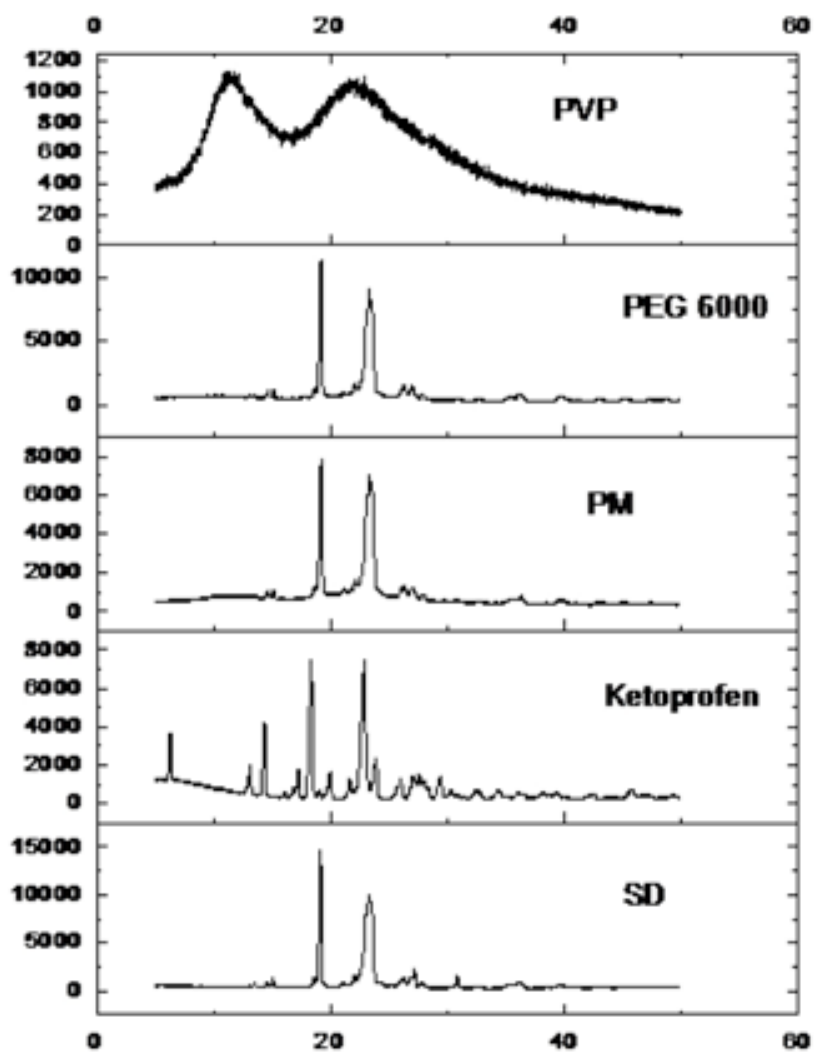

Figure2. Powder X-ray-diffraction of PVP K30, PEG 6000, physical mixture (PM), pure ketoprofen and solid dispersion (SD).

\section{Scanning electron microscopy (SEM)}

SEM photomicrographs of solid dispersion shown in figure 3. On observing the SEM image of solid dispersion, the surface is observed as rough and flaky. 


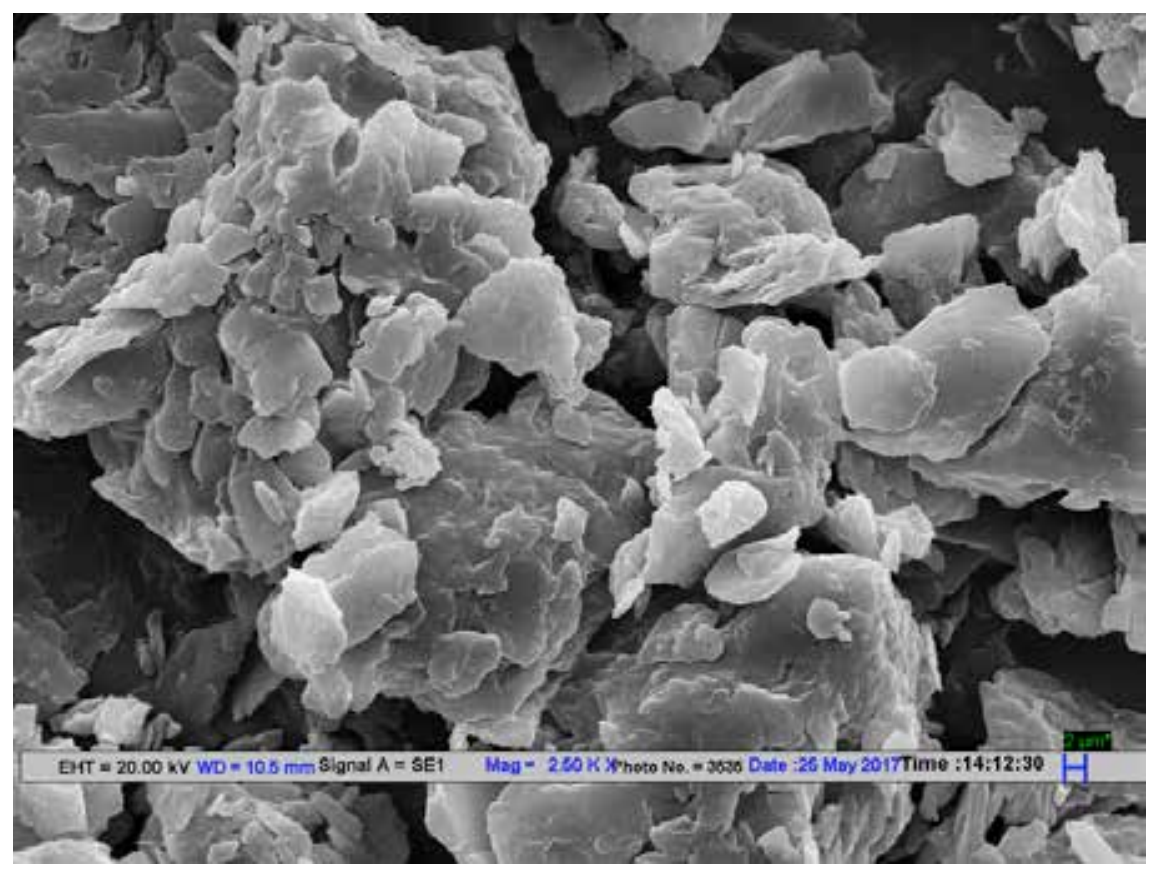

Figure 3. SEM photomicrograph of solid dispersion.

\section{Differential scanning calorimetry (DSC)}

DSC curves obtained for pure ketoprofen, physical mixture and solid dispersion are shown in figure.4. The thermogram of ketoprofen showed an endotherm onset of heating at $91.97^{\circ} \mathrm{C}$ and end of melting point is $97.59^{\circ} \mathrm{C}$ with heat of fusion $(\Delta \mathrm{H}) 93.0185 \mathrm{~J} / \mathrm{g}$, corresponding to its melting point and indicating its crystalline nature. Interestingly, a sharp peak corresponding to the drug was also observed in both the PM and the SD, which in contrast to the thermogram seen with most SDs. It indicates the absence of strong interactions between the drug and the carriers during preparation of the SD. It also suggests that ketoprofen was present in an unchanged crystalline state in the SD. Thus, similar to the XRD findings, these result indicated that ketoprofen was present in an unchanged crystalline state in the $\mathrm{SD}^{40}$. Our results suggest that the enhanced solubility of ketoprofen was not due to the transformation of the crystalline form into an amorphous state, but instead were due to the attachment of the carriers to the surface of poorly water-soluble ketoprofen, converting the hydrophobic drug to hydrophilic form in this solid dispersion. 


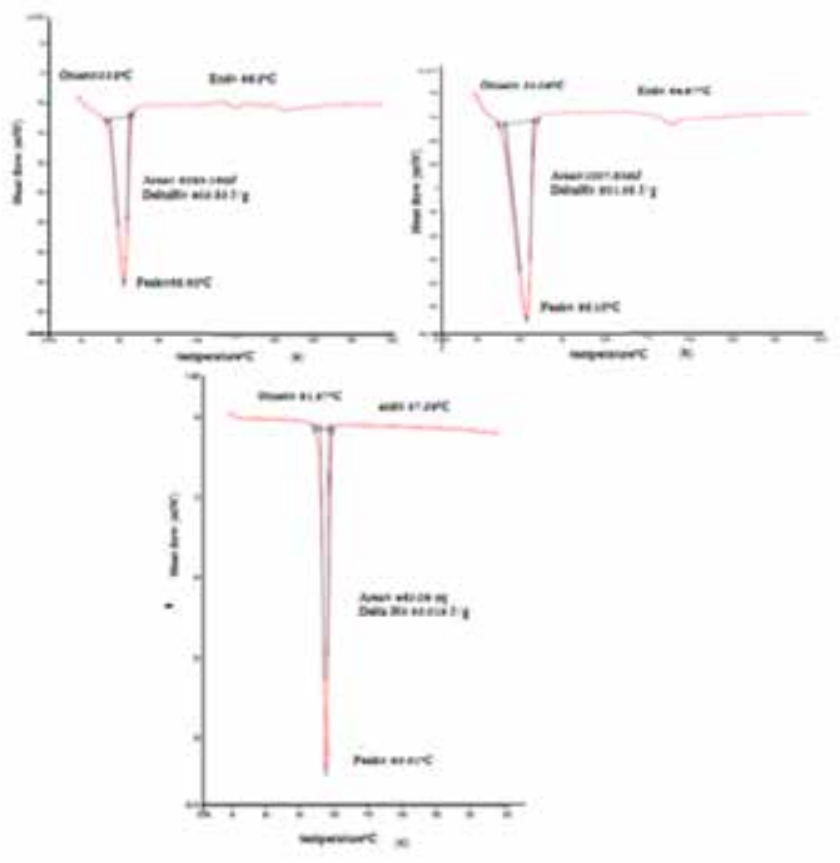

Figure 4. DSC Thermogram of SD (a), PM (b) and ketoprofen (c).

\section{Solubility studies}

The different batches of SD were prepared containing PEG 6000, PVP K-30 and ketoprofen as per the design protocol (Table 1). The pure ketoprofen dispensed a solubility of $14.4 \mu \mathrm{g} / \mathrm{ml}$ in water at room temperature whereas the physical mixture showed solubility of $23.8 \mu \mathrm{g} / \mathrm{ml}$. The physical mixture presented solubility higher than the pure drug because of the polymers (PEG 6000 and PVP K-30) are present. However, the solid dispersion conferred solubility values ranging from $36.2-53.0 \mu \mathrm{g} / \mathrm{ml}$. This increase may be due to formation of soluble complex between drug and polymers whereas the lower solubility in case of physical mixture as compared to SD may be explained on the basis of results obtained from DSC and XRD studies revealing that ketoprofen is still present in crystalline state. 
Table 1. Solubility, in-vitro release, drug content and Gibb's free energy of different batches.

\begin{tabular}{|c|c|c|c|c|c|c|}
\hline Batches & $\begin{array}{c}\text { Conc. Of } \\
\mathbf{P E G ~ 6 0 0 0} \\
(\mathbf{m g})\left(\mathbf{X}_{\mathbf{1}}\right)\end{array}$ & $\begin{array}{c}\text { Conc. Of } \\
\text { PVP K-30 } \\
(\mathbf{m g})\left(\mathbf{X}_{2}\right)\end{array}$ & $\begin{array}{c}\text { Solubility } \\
(\boldsymbol{\mu g} / \mathbf{m l})\left(\mathbf{Y}_{1}\right)\end{array}$ & $\begin{array}{c}\% \text { release } \\
\text { in 60 min. } \\
\left(\mathbf{Y}_{2}\right)\end{array}$ & $\begin{array}{c}\text { Drug } \\
\text { content } \\
(\%)\end{array}$ & $\begin{array}{c}\text { Gibb's } \\
\text { energy } \\
(\mathbf{K J} / \mathbf{m o l})\end{array}$ \\
\hline SD1 & 1000 & 1000 & 36.2 & 77.89 & 86.4 & -3 \\
\hline SD2 & 4000 & 1000 & 47.9 & 89.2 & 82.8 & -4.3 \\
\hline SD3 & 1000 & 2000 & 36.9 & 78.76 & 95.3 & -3.4 \\
\hline SD4 & 4000 & 2000 & 53.0 & 95.32 & 97.9 & -5.7 \\
\hline SD5 & 1000 & 1500 & 35.7 & 76.74 & 88.9 & -2.9 \\
\hline SD6 & 4000 & 1500 & 51.6 & 90.98 & 86.4 & -4.2 \\
\hline SD7 & 2500 & 1000 & 40.8 & 81.34 & 86.4 & -3.6 \\
\hline SD8 & 2500 & 2000 & 52.8 & 92.36 & 96.8 & -4.9 \\
\hline SD9 & 2500 & 1500 & 45.8 & 87.4 & 86.2 & -3.9 \\
\hline SD10 & 2500 & 1500 & 42.5 & 84.39 & 87.6 & -3.1 \\
\hline SD11 & 2500 & 1500 & 42.9 & 86.74 & 87.8 & -3.34 \\
\hline SD12 & 2500 & 1500 & 43.5 & 84.5 & 86.5 & -3.2 \\
\hline SD13 & 2500 & 1500 & 44.7 & 86.12 & 88.0 & -3.8 \\
\hline Ketoprofen & & & 14.4 & 23.5 & & \\
\hline
\end{tabular}

Table 1 shows the results of solubility of different batches of solid dispersions prepared as per the design protocol. The responses generated were fitted into various polynomial models using experimental design. The response solubility was fitted best into quadratic model with square root transformation of the data. The adjusted polynomial equation obtained for the solubility $\left(\mathrm{Y}_{1}\right)$ shown in equation (1) with determination correlation $\left(\mathrm{R}^{2}\right)$ of 0.842 .

$\mathrm{Y}_{1}=6.63+0.5330 \mathrm{X}_{1}+0.2160 \mathrm{X}_{2}$

Table 2 summarizes the results of ANOVA on the response surface model. The polynomial model was found to be significant $(\mathrm{p}<0.05)$ with non-significant lack of fit ( $p>0$. 05). The good correlation between the experimental and predicted response is indicated by higher value of $\mathrm{R}^{2}(>0.8)$. Adequate precision that measures the signal to noise ratio (17.58) was much above the required value of 4 , indicating adequate signal and model fit to navigate the design space. Fig. 5 (a) display the combined effect of concentration of PEG 6000 
\& PVP K-30 on solubility. It can be inferred from the plots that there exists a curvilinear relationship between independent and dependent variables. It is inferred from the plot that higher level of polymers \& ketoprofen results in increase in solubility.

To attain stability a natural tendency to acquire minimum Gibbs energy is always there. The plot of Gibbs free energy against varying concentration of polymers (PEG 6000 \& PVP K-30) and ketoprofen (Fig. 5c) construed that the process is more favorable at higher level of polymers possessing minimum value of $\Delta \mathrm{G}$. Further, all the values of $\Delta \mathrm{G}$ are negative (Table 1) at all levels of carrier demonstrating spontaneity of drug solubilization process.

$\Delta \mathrm{G}=-3.51-0.8167 \mathrm{X}_{1}-0.5083 \mathrm{X}_{2}-0.2500 \mathrm{X}_{1} \mathrm{X}_{2}+0.0431 \mathrm{X}_{1}^{2}-0.6819 \mathrm{X}_{2}^{2}$
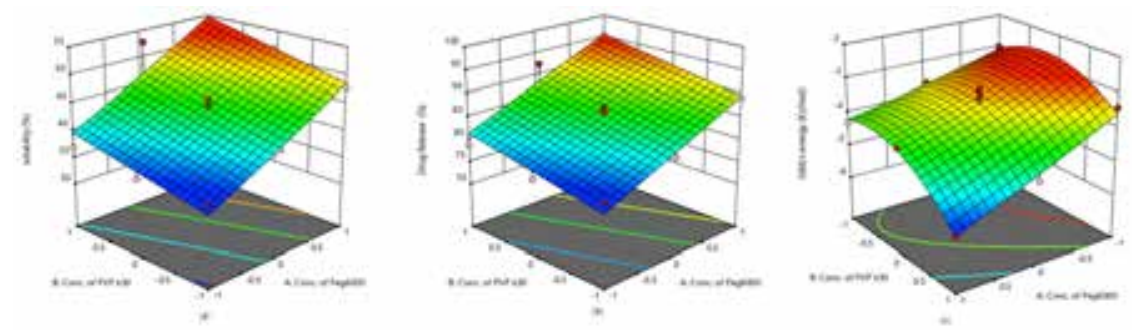

Figure 5. (a,b,c) Response surface plots showing effect of concencentration of PEG 6000 \& PVP

K-30 on solubility $\left(\mathrm{Y}_{1}\right)$, in-vitro release $\left(\mathrm{Y}_{2}\right)$ and Gibb's free energy.

\section{In vitro drug release}

Table 1 shows the in vitro drug release data at $60 \mathrm{~min}$. From these results, it is observed that only $23.5 \%$ of ketoprofen was released in 1 hour from drug solution and $75.4 \%$ from the PM whereas different batches of SD show 76.74 to 95.32\% release of ketoprofen in $1 \mathrm{hr}$ study. The polynomial equation obtained for the dependent variable $\mathrm{Y}_{2}$ (in vitro release) is shown in equation (2).

$\mathrm{Y}_{2}=85.52+7.02 \mathrm{X}_{1}+3.00 \mathrm{X}_{2}$

Table 2 summarizing the results of ANOVA on response surface model (fitted best in cubic model after none transformation of the data). The responses generated were fitted into various polynomials models using the experimental design. It was observed that response in vitro release (Y2) fitted best into cubic response surface model. 
Table 2. Model summary statistic

\begin{tabular}{|c|c|c|c|c|c|c|c|}
\hline \multicolumn{5}{|c|}{ Model } & \multicolumn{2}{c|}{ Lack of Fit } \\
\hline $\begin{array}{c}\text { Response } \\
\text { factor (Y) }\end{array}$ & F-value & Prob.>F & R $^{2}$ & $\begin{array}{c}\text { Adeq. } \\
\text { Prec. }\end{array}$ & C.V (\%) & F-value & Prob.>F \\
\hline Y1 & 33.27 & $<0.0001$ & 0.84 & 17.95 & 2.69 & 4.41 & 0.086 \\
\hline Y2 & 40.89 & $<0.0001$ & 0.86 & 20.17 & 2.42 & 3.28 & 0.135 \\
\hline
\end{tabular}

The polynomial model was found to be significant $(\mathrm{p}<0.05)$ with non-significant lack of fit ( $\mathrm{p}>0$. 05). The higher value of $\mathrm{R}^{2}(>0.9)$ pertinent good correlation between the experimental and predicted response. Adequate precision that estimates the signal to noise ratio (20.17) was much above the required value of 4 , indicating adequate signal and model fit to navigate the design space. Figure 5 (b) display the combined effect of concentration of PEG 6000 \& PVP K-30 on \% release that exhibited a linear relationship between independent and dependent variables, suggested that higher level of PEG 6000 \& PVP K-30 favours the expedited release. The numerical optimization tool using desirability approach was employed to prepare solid dispersion. The optimization of independent variables was done with constraints of maximum solubility and maximum \% release.

The optimization of independent variables was done with constraints of maximum solubility and maximum \% release. The parameters suggested by the design were concentration of PEG 6000 (0.993\%) \& concentration of PVP K-30 (0.985\%) that provide SD with solubility of $54 \mu \mathrm{g} / \mathrm{ml}$ (predicted value $54.23 \mu \mathrm{g} /$ $\mathrm{ml}$ ) and \% release $95.43 \%$ (predicted value 95.87\%). The closer agreement between predicted and observed values indicated the high prognostic ability of the model. Figure 6 displays the in vitro release profile of ketoprofen as pure drug and from the optimized batch of formulation.

A numerical optimization tool of design expert software was used further for calculating the optimal concentration of PVP K-30 and PEG 6000 for preparation of solid dispersion. The optimal calculates parameters were found to be concentration of PEG 6000 (4000 mg) and concentration of PVP K-30(2000 $\mathrm{mg}$ ) which provided us with the drug release is $95.32 \%$.

The optimized batch of ketoprofen containing solid dispersion of PVP K-30 and PEG 6000 was found to batch no. 4 (optimized batch) and drug release is $95.32 \%$ of the drug.

It is clearly observed that the dissolution rate of pure ketoprofen is low because $23.5 \%$ of drug dissolved in 60 min. The resultant study showed that the dis- 
solution of drug from physical mixture was improved (75.4 \%) but the Solid dispersion from resulted in a marked increase of ketoprofen dissolution (95.32 \%) compare to physical mixture at the end of $1 \mathrm{hr}$. Typical mechanism for improvement of dissolution characteristics of drug via solid dispersion are particle size reduction, and improved wettability and dispersibility of ketoprofen due to surface tension lower effect of PVP K-30.

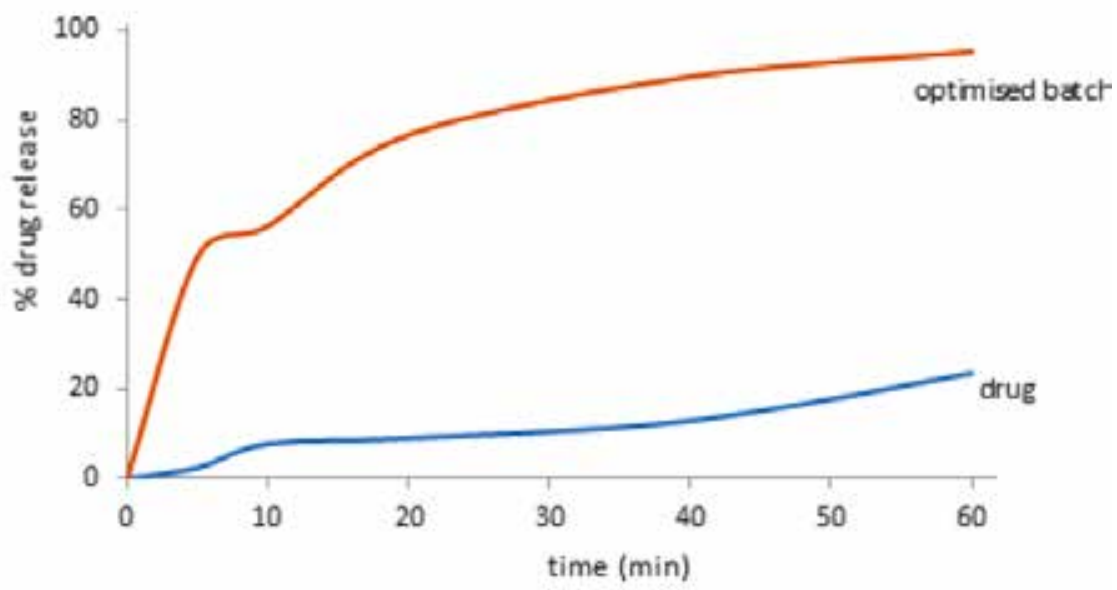

Figure 6. In vitro release profile of drug (pure ketoprofen) and solid dispersion (optimized batch).

The release of ketoprofen from solid dispersion was fitted into various kinetic models to estimate their release kinetics and mechanism of release. The results of release rate data for the formulation fitted best into Higuchi model $\left(\mathrm{R}^{2}=\right.$ $0.917, \mathrm{n}=1.02$ ) of release kinetic. Further, the value of ' $\mathrm{n}$ ' $>1.0$ indicates that the release of ketoprofen from solid dispersion occurs by super-case-2 transport that is the release occurred by relaxtion or erosion of polymer after swelling in biological fluid.

Hot melt method is a fast and simple technique for preparing solid dispersion. The solubility and dissolution rate of ketoprofen from solid dispersion with PVP K-30 and PEG 6000 was markedly increased in comparison to pure ketoprofen and physical mixture. As it is revealed from the DSC and PXRD spectra that ketoprofen is in present in crystalline form but the dissolution rate has been increased. Our results suggest that the enhanced solubility of ketoprofen was not due to the transformation of the crystalline form into an amorphous state, but due to the attachment of the carriers to the surface of poorly water- 
soluble ketoprofen, converting the hydrophobic drug to hydrophilic form in the solid dispersion. The higher dissolution rate of ketoprofen in SD was therefore attributed to improved wetting of crystal surface mainly due to presence of PEG 6000 and PVP K-30 particles, which provoked the solubilization effect. In conclusion, this surface-attached ketoprofen-loaded SD would be of use for delivering poorly water-soluble ketoprofen with enhanced solubility and dissolution, but without crystalline changes.

\section{ACKNOWLEDGEMENTS}

The authors are highly grateful to DST-PURSE New Delhi, Sanction no. SR/ PURSE 2/40 (G) programme, Guru Jambheshwar University of Science \& Technology, Hisar. 


\section{REFERENCES}

1. Kalepu, S.; Nekkanti, V. Insoluble drug delivery strategies: review of recent advances and business prospects. Acta Pharm. Sin. B, 2015, 5, 442-453.Bellantone, R. A. Fundamentals of amorphous systems: thermodynamic aspects. In Amorphous Solid Dispersions (pp. 3-34). 2014, Springer, New York, NY.

2. Ruan, L. P.; Yu, B. Y.; Fu, G. M.; Zhu, D. N. Improving the solubility of ampelopsin by solid dispersions and inclusion complexes. J. Pharm. Biomed. Anal, 2oo5, 38, 457-464.

3. Hancock, B. C.; Zografi, G. Characteristics and significance of the amorphous state in pharmaceutical systems. J. Pharm. Sci. 1997, 86, 1-12.

4. Rautio, J.; Kumpulainen, H.; Heimbach, T.; Oliyai, R.; Oh, D.; Järvinen, T.; Savolainen, J. Prodrugs: design and clinical applications. Nat. Rev. Drug Discov. 20o8, 7, 255.

5. Chiou, W. L.; Riegelman, S. Pharmaceutical applications of solid dispersion systems. $J$. Pharm. Sci. 1971, 6o, 1281-1302.

6. Paradkar, A.; Ambike, A. A.; Jadhav, B. K.; Mahadik, K. R. Characterization of curcuminPVP solid dispersion obtained by spray drying. Int. J. Pharm. 2004, 271, 281-286.

7. Van den Mooter, G.; Wuyts, M.; Blaton, N.; Busson, R.; Grobet, P.; Augustijns, P.; Kinget, R. Physical stabilisation of amorphous ketoconazole in solid dispersions with polyvinylpyrrolidone K25. Eur. J. Pharm. Sci. 2001, 12, 261-269.

8. Fort, J. J.; Krill, S. L.; Law, D.; Qiu, Y.; Porter, W. R.; Schmitt, E. A. U.S. Patent No. 7,364,752. 2008, Washington, DC: U.S. Patent and Trademark Office.

9. Vasconcelos, T.; Costa, P. Development of a rapid dissolving ibuprofen solid dispersion. In PSWC-Pharmaceutical Sciences World Conference (Vol. 23), 2007, 11-130.

10. Maruthapillai, A.; Palanisamy, K.; Sunkara, M. Preparation and characterization of rilpivirine solid dispersions with the application of enhanced solubility and dissolution rate. J. Basic Appl. Sci. 2015, 4, 71-79.

11. Bhatia, M.; Devi, R. Enhanced Solubility and Drug Release of Ketoprofen Using Lyophilized Bovine Serum Albumin Solid Dispersion. Acta Pharm. Sci. 2019, 57, 33-45.

12. Wu, W.; Löbmann, K.; Rades, T.; Grohganz, H. On the role of salt formation and structural similarity of co-formers in co-amorphous drug delivery systems. Int. J. Pharm. 2018, 535, 8694 .

13. Lim, L. M.; The-Thien T.; Wean S. C.; Kunn H. Re-evaluating the presumed superiority of amorphous nanoparticles over amorphous microscale solid dispersion in solubility enhancement of poorly soluble drugs. Eur. J. Pharm. Sci. 2017, 109, 455-463.

14. Goel, S.; Sachdeva, M.; Agarwal, V. Nanosuspension Technology: Recent Patents on Drug Delivery and their Characterizations. Recent Pat. Drug Deliv. Formul. 2019, 13, 91-104.

15. Vedaga, S. B.; Gondkar, S. B.; Saudagar, R. B. Nanosuspension: An emerging trend to improve solubility of poorly water-soluble drugs. J. Drug Deliv. Therap. 2019, 9, 549-553.

16. Azimullah, S.; Sudhakar, C. K.; Kumar, P.; Patil, A.; Usman, M. R. M.; Usman, M. Z. S. Nanosuspensions as a promising approach to enhance bioavailability of poorly soluble drugs: An update. J. Drug Deliv. Therap. 2019, 9, 574-582.

17. Liu, Y.; Wu, F.; Ding, Y.; Zhu, B.; Su, Y.; Zhu, X. Preparation and Characterization of Paclitaxel/Chitosan Nanosuspensions for Drug Delivery System and Cytotoxicity Evaluation In 
Vitro. Adv. Fib. Materials, 2019, 1, 152-162.

18. Kansom, T.; Sajomsang, W.; Saeeng, R.; Rojanarata, T.; Ngawhirunpat, T.; Patrojanasophon, P.; Opanasopit, P. Fabrication and characterization of andrographolide analogue (3A. 1) nanosuspensions stabilized by amphiphilic chitosan derivatives for colorectal cancer therapy. J. Drug Deliv. Sci. Technol. 2019, 54, 101287.

19. Vithani, K.; Hawley, A.; Jannin, V.; Pouton, C.; Boyd, B. J. Solubilisation behaviour of poorly water-soluble drugs during digestion of solid SMEDDS. Eur. J Pharm. Biopharm. 2018, 130, 236-246.

20. He, H.; Lu, Y.; Qi, J.; Zhu, Q.; Chen, Z.; Wu, W. Adapting liposomes for oral drug delivery. Acta Pharm. Sin. B. 2019, 9, 36-48.

21. Pathak, N.; Pathak, P. Applications liposome in cancer drug delivery and treatment: A review. Asian J. Pharm. Res. Develop. 2019, 7, 62-65.

22. Kim, A. R.; Lee, N. H.; Park, Y. M.; Park, S. N. Preparation and characterization of novel pseudo ceramide liposomes for the transdermal delivery of baicalein. J. Drug Deliv. Sci. Technol. 2019, 52, 150-156.

23. Goswami, P.; Changmai, A.; Barakoti, H.; Choudhury, A.; Dey, B. K. A brief review on Liposomal Drug Delivery System. J. Pharm. Adv. Res. 2018, 1, 362-368.

24. Jani, R. K.; Pandya, M.; Rathod, H. Liposomes encapsulating cyclodextrin enclosed hydrophobic anti-cancer drugs: a novel drug delivery system for cancer. J. Drug Deliv. Therap. 2019, 9, 598-605.

25. Zajc, N.; Obreza, A.; Bele, M.; Srčič, S. Physical properties and dissolution behaviour of nifedipine/mannitol solid dispersions prepared by hot melt method. Int. J. Pharm. 20o5, 291, 51-58.

26. Karanth, H.; Shenoy, V. S.; Murthy, R. R. Industrially feasible alternative approaches in the manufacture of solid dispersions: A technical report. AAPS PharmSciTech, 2oo6, 7, E31-E38.

27. Khaleel, N. Y.; Abdulrasool, A. A.; Ghareeb, M. M.; Hussain, S. A. Solubility and dissolution improvement of ketoprofen by solid dispersion in polymer and surfactant using solvent evaporation method. Acad Sci IJPPS, 2011, 3, 431-435.

28. Yadav, P. S.; Kumar, V.; Singh, U. P.; Bhat, H. R.; Mazumder, B. Physicochemical characterization and in vitro dissolution studies of solid dispersions of ketoprofen with PVP K3O and d-mannitol. Saudi Pharm. J. 2013, 21, 77-84.

29. Jachowicz, R. E. B. B. A.; Nürnberg, E.; Pieszczek, B.; Kluczykowska, B.; Maciejewska, A. Solid dispersion of ketoprofen in pellets. Int. J. Pharm. 2ooo, 206, 13-21.

30. Margarit, M. V.; Rodríguez, I. C.; Cerezo, A. Physical characteristics and dissolution kinetics of solid dispersions of ketoprofen and polyethylene glycol 60oo. Int. J. Pharm. 1994, 108, 101-107.

31. Barmpalexis, P.; Koutsidis, I.; Karavas, E.; Louka, D.; Papadimitriou, S. A.; Bikiaris, D. N. Development of PVP/PEG mixtures as appropriate carriers for the preparation of drug solid dispersions by melt mixing technique and optimization of dissolution using artificial neural networks. Eur. J Pharm. Biopharm. 2013, 85, 1219-1231.

32. Bikiaris, D. N. Solid dispersions, part I: recent evolutions and future opportunities in manufacturing methods for dissolution rate enhancement of poorly water-soluble drugs. $E x-$ pert Opin. Drug Deliv. 2011, 8, 1501-1519. 
33. Tran, T. H.; Poudel, B. K.; Marasini, N.; Chi, S. C.; Choi, H. G.; Yong, C. S.; Kim, J. O. Preparation and evaluation of raloxifene-loaded solid dispersion nanoparticle by spray-drying technique without an organic solvent. Int. J. Pharm. 2013, 443, 50-57.

34. Nguyen, T. N. G.; Tran, P. H. L.; Van Tran, T.; Van Vo, T.; Truong-Dinh Tran, T. Development of a modified-solid dispersion in an uncommon approach of melting method facilitating properties of a swellable polymer to enhance drug dissolution. Int. J. Pharm. 2015, 484, 228234.

35. Patel, R.; Patel, M. Preparation, characterization, and dissolution behavior of a solid dispersion of simvastatin with polyethylene glycol 4000 and polyvinylpyrrolidone K30. J. Dispers. Sci. Technol. 2008, 29, 193-204.

36. Lee, S. N.; Poudel, B. K.; Tran, T. H.; Marasini, N.; Pradhan, R.; Im Lee, Y.; Kim, J. O. A novel surface-attached carvedilol solid dispersion with enhanced solubility and dissolution. Arch. Pharm. Res. 2013, 36, 79-85.

37. Yan, Y. D.; Sung, J. H.; Kim, K. K.; Kim, D. W.; Kim, J. O.; Lee, B. J.; Yong, C. S.; Choi, H. G. Novel valsartan-loaded solid dispersion with enhanced bioavailability and no crystalline changes. Int. J. Pharm. 2012, 422, 202-210.

38. Oh, D. H.; Park, Y. J.; Kang, J. H.; Yong, C. S.; Choi, H. G. Physicochemical characterization and in vivo evaluation of flurbiprofen-loaded solid dispersion without crystalline change. Drug Deliv., 2011, 18, 46-53.

39. Joe, J. H.; Lee, W. M.; Park, Y. J.; Joe, K. H.; Oh, D. H.; Seo, Y.G.; Woo, J. S.; Choi, H. G. Effect of the solid-dispersion method on the solubility and crystalline property of tacrolimus. Int. J. Pharm. 2010, 395, 161-166. 